Estudios sobre armas antiguas, arte militar $\mathrm{y}$ vida cultural en oriente y occidente

XXXVIII (2018), pp. 159-176

ISSN: 0436-029X

https://doi.org/10.3989/gladius.2018.09

\title{
CAÑONES AL ÓLEO. UNA ALTERNATIVA PARA LA ARTILLERÍA DE CARTAGENA DE INDIAS A FINES DEL SIGLO XVIII*
}

\author{
OIL CANNONS. AN ALTERNATIVE FOR THE ARTILLERY OF CARTAGENA \\ DE INDIAS AT THE END OF THE EIGHTEENTH CENTURY
}

POR

\author{
Manuel Gámez CASAdo**
}

\section{RESUMEN - ABSTRACT}

El presente artículo tiene como objetivo analizar algunos de los aspectos menos conocidos de la artillería de Cartagena de Indias durante el siglo XVIII. Entre éstos, la realización de distintos experimentos sobre los cañones de hierro permitió superar los desperfectos generados por el clima mediante la utilización de un nuevo barniz. Además, se incluye un estudio sobre las aportaciones que los militares españoles realizaron para mejorar el artillado de dicha ciudad. Para ello, partiendo de anteriores publicaciones y analizando fuentes primarias, se examinarán los modelos de cañones utilizados en las fortificaciones, ahondando tanto en la relación existente entre ingeniería y artillería, como en los mecanismos de fabricación e importación del armamento desde la Península Ibérica a América.

The objective of this article is to analyze some aspects of the Cartagena de Indias artillery during the 18th century. Among these, the realization of different experiments on the iron cannons allowed to overcome the damages generated by the climate through the use of a new varnish. In addition, a study is included on the contributions that the Spanish military made to improve the artillery of said city. To do this, the cannon models will be examined, studying the relationship between engineering and artillery. The mechanisms of manufacture and import of armament from the Iberian Peninsula to America will also be studied.

\section{Palabras Clave - Keywords}

Artillería; Guerra; Cañones; Cartagena de Indias; Siglo XVIII.

Artillery. War. Cannons. Cartagena de Indias. 18th century.

\section{Cómo CITAR ESTE ARTículo / Citation}

Gámez Casado, M. (2018): «Cañones al óleo. Una alternativa para la artillería de Cartagena de Indias a fines del siglo XVIII». Gladius, XXXVIII: 159-176. https://doi.org/10.3989/gladius.2018.09

* El presente trabajo forma parte de los resultados obtenidos dentro del proyecto de investigación I+D «Ingenieros militares en el Caribe y el Golfo de México durante el siglo XVIII. Diálogo cultural, circulación trasnacional y conflictos globales HAR2015-63805-P», financiado por el Ministerio de Economía y Competitividad del Gobierno de España.

** Departamento de Historia del Arte. Facultad de Geografía e Historia. Universidad de Sevilla. mgamez@us.es / ORCID iD: https://orcid.org/0000-0002-5539-1104. 


\section{CARTAGENA DE INDIAS EN EL CONTEXTO DEFENSIVO DEL CARIBE}

La imagen urbana de Cartagena de Indias ha estado protagonizada por sus murallas, elementos definitorios de su perfil y garantía de su supervivencia. Toda una serie de proyectos defensivos diseñados por los más afamados ingenieros militares, desde Antonelli hasta Anguiano, se sucedieron en un intento por preservar el que era el puerto comercial más importante de cuantos poseyó la Corona española en el Caribe sur. Por su trascendental actividad mercantil, pues en la costa de Cartagena de Indias arribaban los navíos partidos desde Portobelo con rumbo a la Península Ibérica, los distintos monarcas aspiraron a conseguir la más eficaz de las defensas (Véase Kuethe y Kennet, 2014). Ciertamente, hasta el reinado de Carlos III no se logró tal propósito cuando, tras los destrozos originados por el ataque del vicealmirante inglés Edward Vernon en 1741, se destinaron a Cartagena de Indias a experimentados ingenieros con el fin de diseñar el proyecto general de defensa de la ciudad (El propio vicealmirante Vernon escribió una serie de documentos relativos a su ataque. Vernon, 1744. Además, consúltese Restrepo Canal, 1941; Calderón Quijano, 1942; Zapatero, 1957; Lucena Salmoral, 1973; Kuethe, 1974; Serrano Álvarez, 2016 y López Guzmán y Cabrera, 2017).

Dicho plan, ideado por Lorenzo de Solís y culminado por Antonio de Arévalo, se basaba en asegurar el canal de Bocachica, que era el único acceso a la bahía. Para ello se reforzó la batería de San José y se ejecutaron de nueva planta la de Santa Bárbara y el fuerte de San Fernando (Gámez, 2017a). Asimismo, se terminó de cerrar el canal de Bocagrande mediante la construcción de un dique y se modernizó el denostado castillo de San Felipe de Barajas, símbolo de la resistencia de Cartagena de Indias y único bastión del arrabal de Getsemaní (Zapatero, 1979: 126-201). Todo ello, sumado a otra serie de reformas de menor entidad, configuró el sistema de defensa más complejo de cuantos existieron en Nueva Granada, superando lo diseñado en ciudades como Portobelo, Puerto Cabello o Santa Marta. Como se puede comprobar en el plano general de Cartagena de Indias, la disposición de las distintas fortificaciones permitía tanto controlar el acceso por Bocachica, como defender la bahía interior de la ciudad, blindando las distintas áreas de la plaza con el fin de protegerla ante cualquier ataque enemigo (Fig. 1). El número de construcciones defensivas ejecutadas y el avanzado diseño de las mismas son argumentos suficientes para aseverar que lo construido en la bahía de Cartagena superó a lo dispuesto en otros puntos del Caribe.

Sin embargo, era evidente que aquella plaza que contase con resistentes fortificaciones pero adoleciese de una artillería eficaz vería mermada sus posibilidades de defensa (Véase Vigón, 1947). Esta teoría era bien conocida por las milicias españolas destinadas a Tierra Firme a fines del siglo XVIII, precisamente cuando continuas disputas amenazaban el control político del territorio. De entre éstas, caben citar los enfrentamientos relacionados con la Guerra del Asiento, considerado el conflicto de mayor trascendencia de cuantos acaecieron en aguas americanas. Otra amenaza incesante para la Corona suponía la presencia inglesa en puntos estratégicos del Caribe, caso de Jamaica, lo que les permitía mantener un contrabando permanente con las tribus indígenas en detrimento del dominio económico hispano. Justamente para solventar esta problemática, se fundaron nuevos Cuerpos milicianos como los guardacostas reales, cuyas expediciones al Darién supusieron un incremento de la protección territorial española durante las últimas décadas de la centuria (Gámez Casado, 2018).

Pero no debe pensarse que estas medidas solo afectaban a la defensa de los puertos caribeños, ya que desde la Corte también se estimó imprescindible proteger las rutas comerciales existentes entre la Península y América. A través de ellas llegaban, además de otros productos

y metales nobles, el cobre y el estaño procedentes de las minas de México y Perú, que suplían la carencia de estos minerales en los pozos peninsulares. La importancia de asegurar esas rutas 


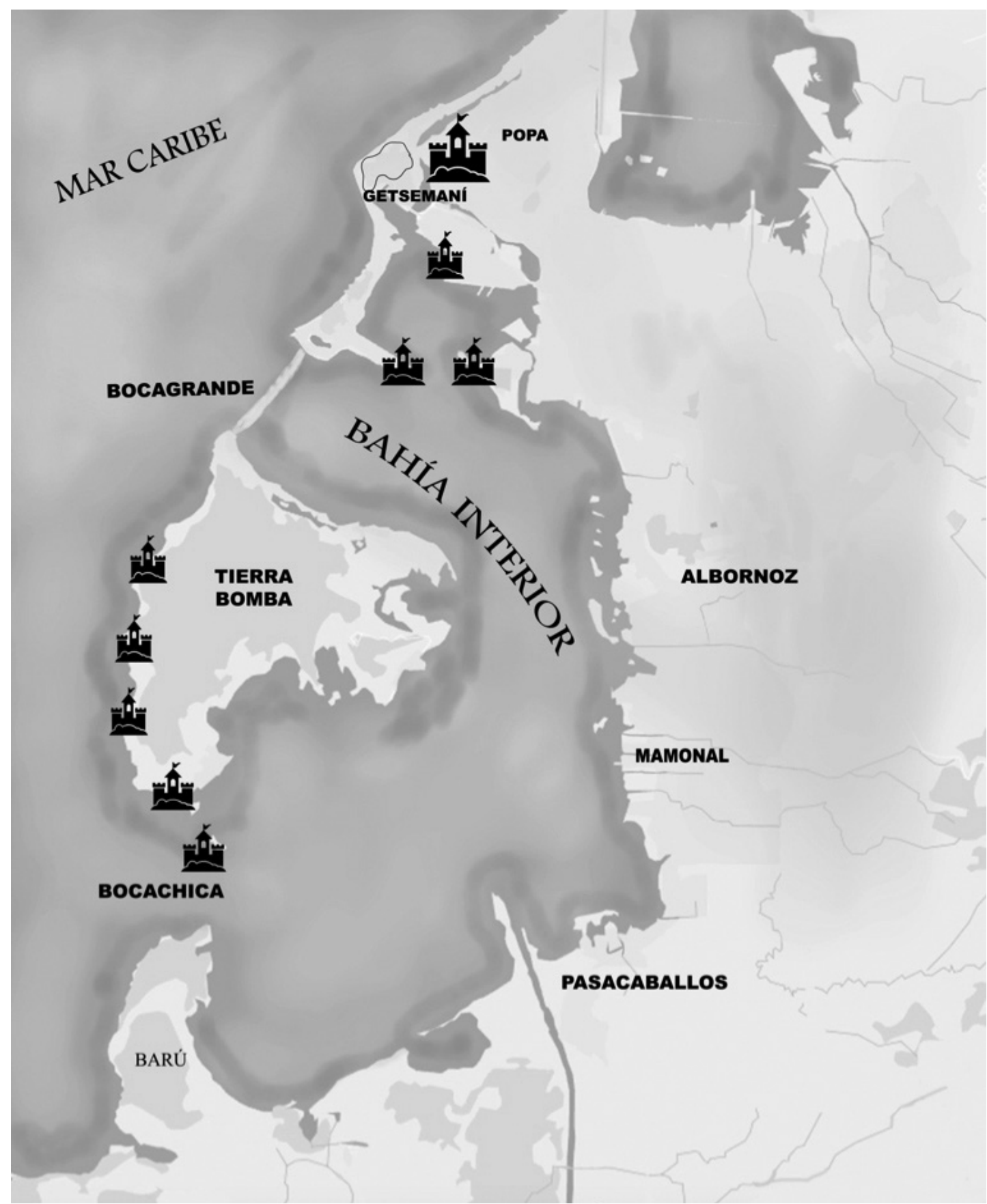

Figura 1. Sistema defensivo de Cartagena de Indias tras el ataque del vicealmirante Vernon en 1741.

residía en la imperiosa necesidad de que dichos metales llegasen correctamente a las fábricas españolas de artillería, especialmente a la instalada en Sevilla, pues eran esenciales para la producción de cañones de bronce (Fig. 2) (Mora Piris, 1997: 326-329. Igualmente, del mismo autor puede consultarse Mora Piris, 1993). 


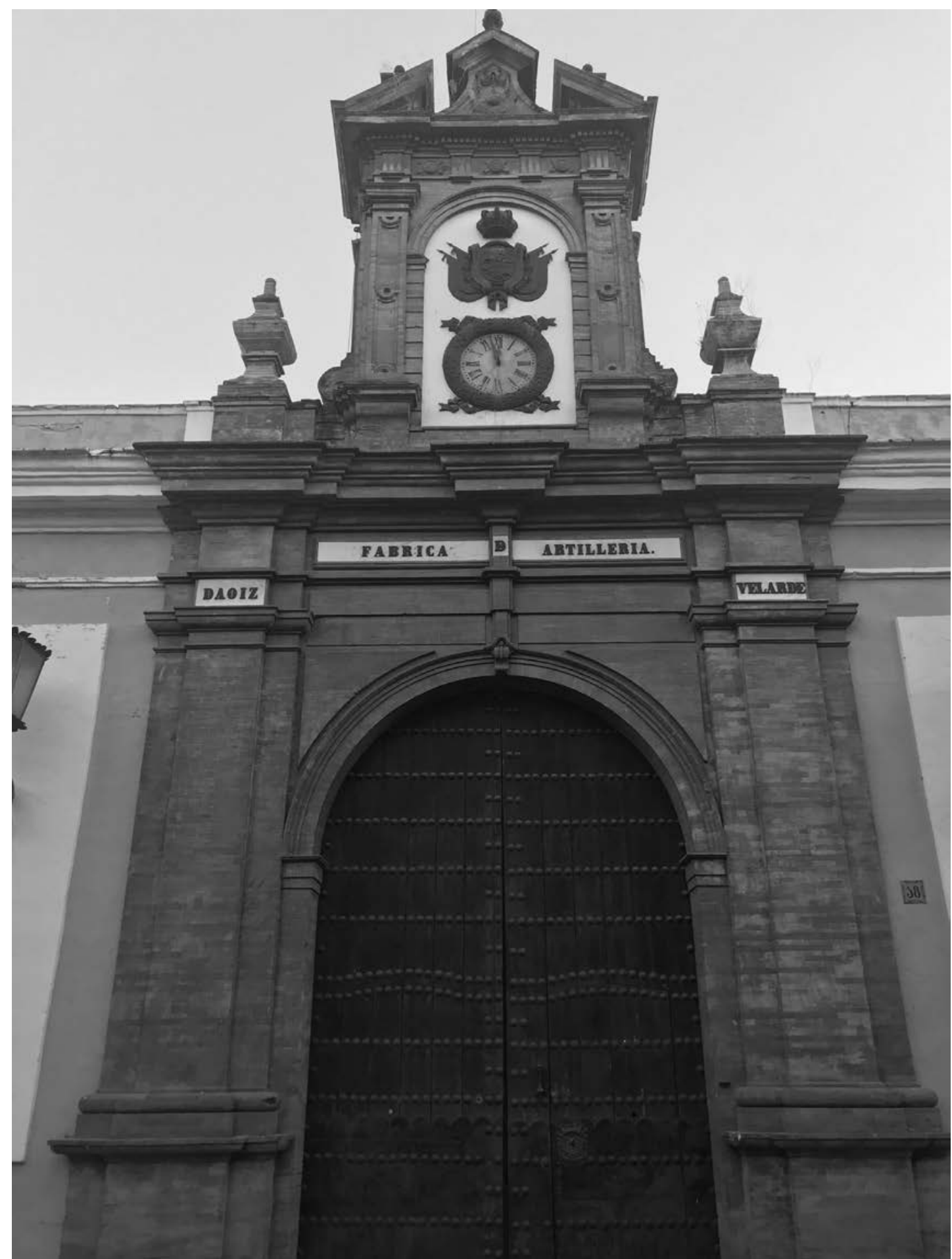

Figura 2. Fachada de la Real Fábrica de Artillería de Sevilla. Fotografía del autor. 


\section{SOBRE LAS PROPIEDADES DE LOS METALES Y LA FUNDICIÓN DE LOS CAÑO- NES.}

No obstante, la protección de las rutas transoceánicas no era garantía de mejora en la fabricación de las armas españolas. Habida cuenta de la impureza de los metales americanos, las factorías metalúrgicas hispanas centraron sus esfuerzos en propiciar importantes avances científicos que mejorasen las técnicas de aleación y fundición (Fueron numerosas las fábricas de artillería construidas en la península, especializándose cada una de ellas en distintas armas. Así, en La Cavada se construían la mayor parte de los cañones de hierro, mientras que en Sevilla se hacía lo propio con los de bronce. Rabanal Yus, 1990: 75-76. La naturaleza de cada una de estas factorías fue recogida por Azpiroz y Arizcun, 1875).

La intención era superar el retrasado sistema de producción basado en los preceptos de Luis Collado de Lebrija, autor del principal tratado de artillería escrito durante el siglo XVI. En este texto, dedicado al rey Felipe II y publicado en 1582, el ingeniero partió de una reseña sobre la historia de la artillería para continuar describiendo minuciosamente distintos aspectos relacionados con el arte militar. Entre los temas desarrollados destacan la sistematización de los distintos procedimientos de fundición de cañones, las aclaraciones sobre el montaje de las armas y las descripciones acerca de otros ejercicios artilleros, tales como la fabricación de minas o de fuegos artificiales. De entre todos los métodos, Collado corroboró la eficacia de la fundición de cañones mediante moldes, convirtiéndose en el más utilizado en las factorías. Sin embargo, advirtió del peligro que suponía descuidar estas matrices, pues ello afectaría al proceso de fundición del cañón y, en consecuencia, a su efectividad en el disparo (Collado, 1592: 9-12). Su minuciosa descripción, unido a la extraordinaria difusión del tratado entre los círculos militares españoles, lo convirtió en referente para las fábricas hispanas.

Incluso, las propuestas de Collado fueron la base de los textos escritos durante la siguiente centuria, siendo ejemplo de ello el tratado redactado por Alonso Barba, publicado en 1640 (Barba, 1640). Basado en las ideas surgidas a fines del Quinientos, el escritor onubense describió el modo en que tratar los distintos minerales, acercándose a corrientes como el alquimismo y centrando sus esfuerzos en relacionar naturaleza, filosofía y pensamiento con el fin de alcanzar el máximo conocimiento del entorno. Sin duda, su escrito fue una aportación sobresaliente, considerándose un antecedente de la ingente tratadística del siglo XVIII y de los nuevos avances ilustrados.

En este sentido, no fue hasta el siglo XVIII cuando se superaron las teorías mencionadas, surgiendo otra literatura que arrojaba nuevas luces a lo conocido. De los escritos publicados propios del pensamiento moderno siempre alcanzaron un especial desarrollo los relativos a la fundición del metal, pues además de advertir sobre los peligros ya conocidos, se proponían nuevas técnicas en favor del avance artillero. Por eso no debe extrañar que el tratado escrito por el matemático y científico José Díaz Infante, publicado en 1740, fuese utilizado con asiduidad en los contextos fabriles (Díaz Infante, 1740). Con admirable precisión y hábil minuciosidad legó una serie de dieciséis reflexiones sobre los procesos de fusión del bronce, acompañados de interesantes explicaciones acerca de la disposición de los talleres, del uso de los hornos y de oportunos dibujos que supusieron una actualización de las técnicas artilleras de fines del Setecientos. Entre éstos, destaca la planta y la sección de un horno de afinos, pues, mediante su correcta utilización, el hierro alcanzaba su máxima pureza, proponiendo el uso de esta técnica como remedio para los problemas metalúrgicos españoles (Fig. 3).

El propio Díaz Infante comentó las propiedades de los metales indianos, ahondando en los problemas que ofrecían las armas que la Corona enviaba a los territorios de Ultramar. Sus teorías recogieron la tradición artillera francesa, asentada en España tras la Guerra de Sucesión. 


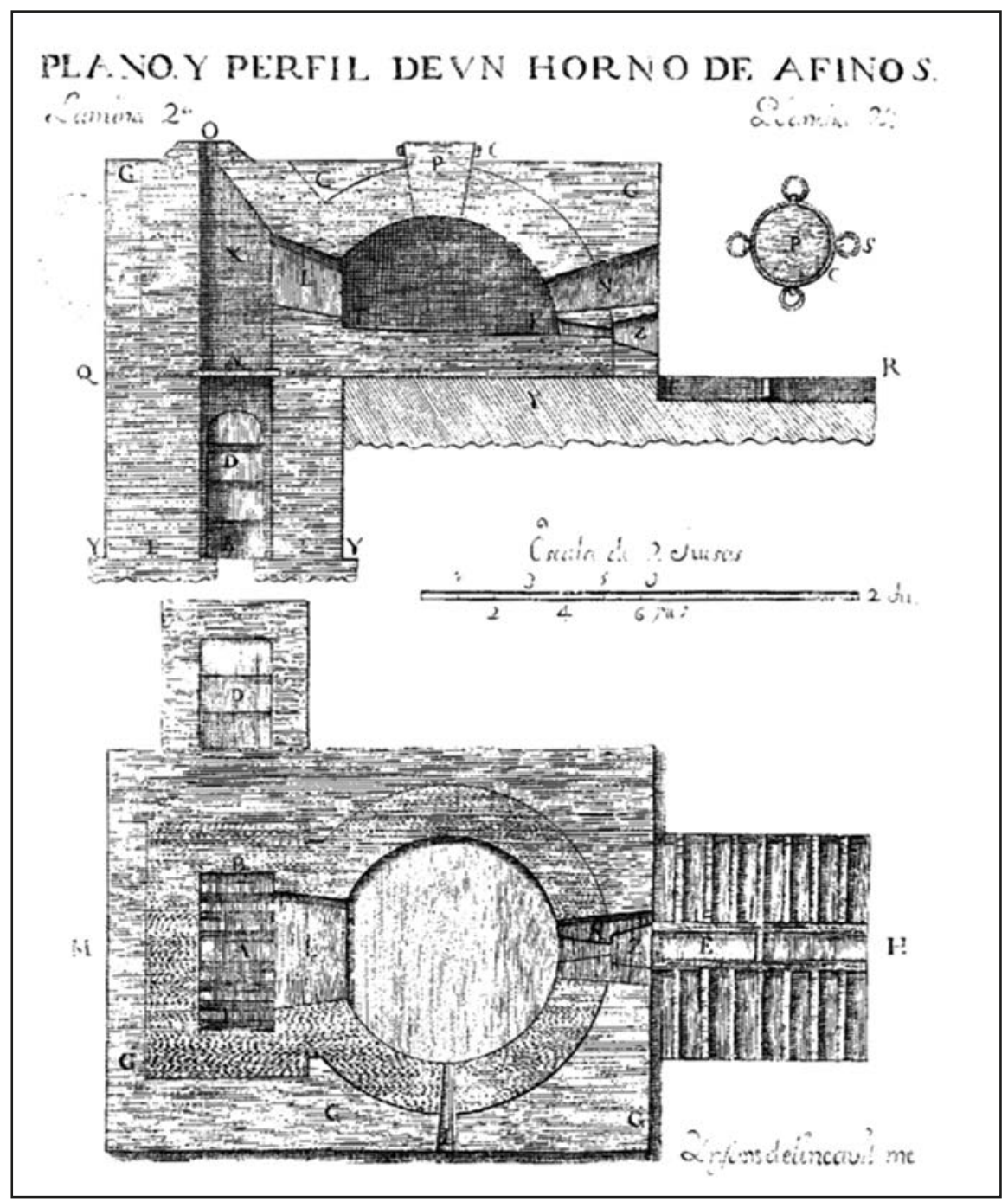

Figura 3. «Plano y perfil de un horno de afinos». José Díaz Infante (1740). Pirometalia absoluta o arte de fundidores. Palma, Imprenta de Miguel Cerdá.

Prueba de ello es que de varios inconvenientes que apunta Díaz sobre la utilización de minerales americanos para la fabricación de cañones ya dio cuenta el célebre Sébastien François Bigot, quien reconoció que el mejor estaño para obtener el bronce se encontraba en Inglaterra (Bigot, 1737).

No fue solo Díaz quien asumió las ideas francesas, pues es bien conocido como distintos oficiales de artillería recorrieron el país galo para formarse en la industria del metal, buscando una renovación de las denostadas técnicas de fabricación de armas aún utilizadas en España (Helguera Quijada, 1983: 468). Incluso, propiciado por la firma del primer Pacto de Familia en 1733, llegaron distintos fundidores franceses que implantaron nuevas técnicas de fabricación de cañones. Este avance tecnológico, favorecido por la aparición en los talleres españoles de los maestros que trabajaban para los Borbones, originó un mejor conocimiento del sistema artillero galo, considerado el más desarrollado de cuantos existían. Además, mediante la Real Ordenanza de 1743, promulgada por el rey Felipe V, se adaptó el método propuesto por el 
general de artillería francés La Valliere, basado en el uso de piezas largas y de alto calibre para defender las plazas. Vigente hasta la segunda mitad del siglo XVIII, el citado método fue denostado tras imponerse el ideado por el general francés Gribeauval, adaptando los cañones a las nuevas estrategias de defensa propias de los últimos años de la centuria. Es más, dentro de los militares españoles, la lectura de ambos modelos de defensa tuvo numerosas consecuencias, siendo ejemplo de ello la inclusión en el tratado de Tomás de Morla de las diferencias existentes entre los modelos de La Vallìere y Gribeauval (De Morla, 1784: 451).

Conocidos estos avances tecnológicos y estas teorías en los talleres metalúrgicos peninsulares en los nuevos contextos borbónicos, el pase a las Indias se produjo a través de prestigiosos industriales europeos que, como Friedrich Sonneschemidt y Thaddeus von Nordenflicht, aprovecharon sus estancias al otro lado del Atlántico para implantar los novedosos procesos de fundición de cañones en las fábricas indianas (López Piñero, 1988: 265-278). Todo ello se entiende en un continuo traslado de ideas, métodos y proyectos hacia los territorios de Ultramar, englobado en un movimiento de transferencia cultural ampliable a otras disciplinas militares, artísticas y científicas.

\section{UN CASO PARTICULAR: LA CONSERVACIÓN DE LA ARTILLERÍA EN CARTAGENA DE INDIAS DURANTE EL SIGLO XVIII.}

Con motivo de la difusión de las teorías esbozadas en las líneas anteriores, los investigadores españoles emprendieron a fines del siglo XVIII la búsqueda de nuevos métodos que corrigiesen el deterioro generado en la artillería de las plazas caribeñas por acción de los agentes climáticos. De acuerdo con la necesidad de salvar las deficiencias de los cañones indianos, pues de ellos dependían buena parte de la defensa española, los militares se comprometieron a iniciar una serie de experimentos que mejorasen la conservación del armamento. De entre las ciudades más afectadas por esas limitaciones, Cartagena de Indias destacó por el alto grado de salitre al que estaban expuestos sus cañones, afectando principalmente a los fabricados en hierro. El principal problema residía en la formación de costras superficiales que descomponían la capa protectora de alquitrán aplicada al final del proceso de fundición. Con el fin de evitarlo, parece, por las noticias encontradas, que se realizaron varios ensayos para reparar tales deterioros, atendiéndose en las líneas siguientes al novedoso sistema ideado en Cartagena de Indias en los últimos años de la centuria (La adaptación de los métodos de fabricación europeos a la realidad americana no siempre resultó exitosa, pues las condiciones climatológicas afectaban a la conservación del hierro utilizado. Así, además de en Cartagena de Indias, se experimentó con otras técnicas en distintas ciudades americanas, cuyos casos han sido estudiados por Cisneros Guerrero, 2003 y Baeza Martín, 2005).

Así, analizando una documentación inédita localizada en el Archivo General de la Nación de Colombia, se estudiará la práctica desarrollada en dicha plaza por distintos militares con el fin de obtener una nueva técnica de barnizado de cañones férreos. Con ello, no solo se aporta un estudio que ahonda en el conocimiento sobre la artillería de Cartagena de Indias durante el Setecientos, sino que también se profundizará en el desarrollo científico y técnico conseguido en las distintas plazas americanas, pues la realidad geográfica de los territorios de Ultramar complicaba la utilización de las armas empleadas en los conflictos bélicos europeos.

Bien sabido es como tras la crisis generada por la ofensiva del vicealmirante inglés Vernon en 1741, la gobernación de Cartagena de Indias se preocupó de equipar sus fortificaciones con suficientes cañones como para cubrir la amplitud de su territorio. Este interés constituyó uno de los principales hitos dentro de las reformas promulgadas por el gobierno de Carlos III, monarca siempre preocupado por renovar los sistemas de defensas americanos y para el que 
trabajaron reconocidos ingenieros (Morales, 2016. Anterior a este hecho, el barón de Pointis atacó a la ciudad de Cartagena de Indias en 1697, necesitándose de una rápida reposición de la artillería. Para ello, Juan Díaz Pimienta, gobernador y capitán general de la plaza, firmó un contrato con el Consulado de Sevilla por el que se comprometía a financiar tal recuperación, siendo un antecedente de las competencias promulgadas por Carlos III en materia de defensa para la ciudad. Al respecto, véase Gómez Pérez, 1985 y Gámez Casado, 2017b).

En este sentido, durante la segunda mitad del siglo XVIII, la Corona incrementó su inquietud por mejorar la capacidad militar y naval del ejército español, relegando otros aspectos administrativos que desembocaron en un endeudamiento de las arcas estatales (Rodríguez Casado, 1956. Un interesante estudio sobre los gastos en defensa de la Corona española durante el Setecientos es el escrito por Andújar Castillo, 2004). En consecuencia, el gasto público generado tras la inversión en las defensas indianas afectó a la economía nacional, a pesar de que el reformismo borbónico no tuviese otra opción ante el deplorable estado de la artillería (Flo-

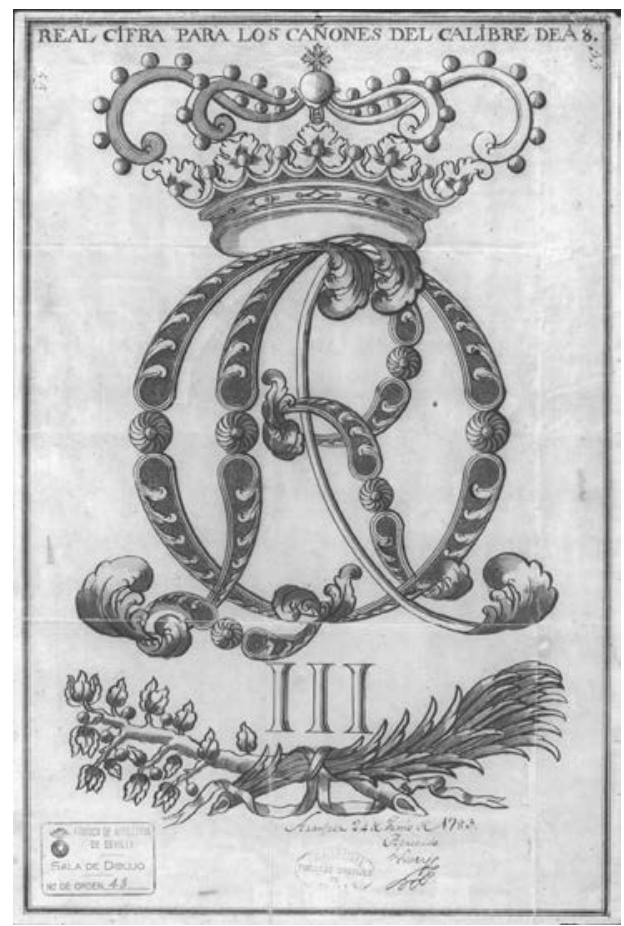

Figura 4. Real Cifra de Carlos III para los cañones del calibre de a 8. Aranjuez, 24 de junio de 1783. Archivo General de Andalucía. F.A.S. Mapas, planos y dibujos, A.0.5.

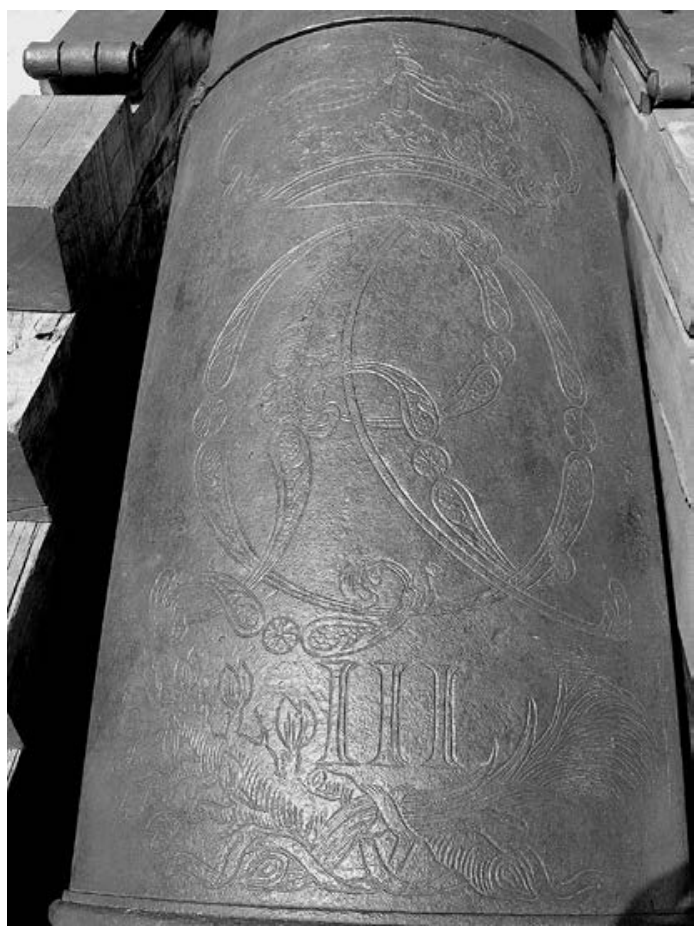

Figura 5. Cañón de bronce con el escudo de Carlos III. Castillo de San Felipe de Barajas. Cartagena de Indias. Fotografía del autor.

res Morón, 1997: 96-98). Si bien, ello permitió un amplio desarrollo de las milicias españolas, tanto en lo referido al diseño de fortificaciones, actualizando los modelos de baterías, castillos y murallas, como en lo tocante al armamento, alcanzándose una especialización insólita hasta la fecha. Por esta razón, existen numerosos cañones que conservan la Real Cifra de las fundiciones de bronce financiadas durante el gobierno de Carlos III, denotando un aumento en la producción artillera y en la exportación del armamento hacia el Nuevo Mundo (Figs. 4 y 5). 
Ciertamente, más allá de cuestiones cuantitativas, el Real Cuerpo de Artillería hispano buscaba modernizar sus armas, facilitando su fabricación, sus traslados y el almacenamiento de la pólvora y los distintos pertrechos, lo que generaría una estructura defensiva que asegurara la plaza ante las amenazas enemigas (Estas mismas necesidades defensivas surgieron en otras ciudades americanas durante el siglo XVIII, cuyos principales ejemplos fueron estudiados por Claro Delgado, 1997). Además, el hecho de que la fundición de los cañones se llevase a cabo en las fábricas peninsulares necesitaba de una flota que trasladase las distintas piezas hasta las fortificaciones americanas. Así, la condición de ciudad portuaria de Cartagena de Indias facilitaba la operatividad de estos desplazamientos, constituyéndose una red de distribución de armas comparable al intercambio de otras mercancías. En este sentido, desde que el gobernador Pedro Fidalgo informase en 1737 que solo se contaban con 90 cañones útiles con cureñas, se pasó durante el gobierno de Roque de Quiroga a contar con un máximo de 392 piezas (Marchena Fernández, 1982: 382-382). Este ilustrativo ejemplo muestra la mejora en la distribución de los cañones desde las distintas fábricas hasta las fortificaciones de Cartagena de Indias, existiendo una evidente preocupación por recuperar la mejor de las defensas tras la crisis sucedida a mediados del siglo.

No obstante, la eficacia alcanzada con el envío de armamento desde la Península Ibérica a Cartagena de Indias durante el reinado de Carlos III era muy distinta a lo vivido durante el resto del siglo XVIII. El principal problema era el retraso producido en el pase de las solicitudes de armamento a las fábricas de artillería, pues dichos documentos debían pasar por distintos cauces administrativos, transcurriendo varios meses hasta que los cañones alcanzaban sus destinos. La situación no mejoraba si se responsabilizaban del transporte otras empresas, caso de la Compañía Guipuzcoana, encargada de llevar a las Indias las unidades destinadas a la defensa para la Guerra del Asiento. Responsable de tal menester, la expedición no surtió de suficientes armas a las fortificaciones caribeñas, ya que partieron tarde y sufrieron distintos contratiempos que les obligaron a arribar a Puerto Rico.

Esta falta de operatividad en la distribución armamentística era extensible a la fabricación de cureñas, pues tan solo en contadas ocasiones había suficientes para el número de cañones empleados. Así, la cantidad de cureñas existentes siempre fue inferior a la de cañones, de modo que tan solo en 1699, 1739 y 1763 se equipararon la cantidad de ambos elementos (Gómez Pérez, 1997: 51-54). Dichas fechas coinciden con el restablecimiento de las defensas de Cartagena de Indias tras ataques enemigos, denotando un interés por parte de la gobernación en restituir la artillería deteriorada. A esta operación ayudó la fundación durante el gobierno de Pedro Messía de la Cerda de la Fábrica de Pólvora de Santa Fe de Bogotá, considerada el principal centro distribuidor de munición del virreinato de la Nueva Granada (Velásquez Arango, 2015).

Por otro lado, el hecho de que Cartagena de Indias sea una plaza marítima condicionaba la localización de sus cañones, debiendo situarse a una distancia suficiente como para alcanzar a los barcos enemigos. Éstos eran objetivos móviles, lo que determinaba no solo la posición, sino también las longitudes de tiro, obligando a adaptarse a cada una de estas variantes desde tierra firme. Por ello, al depender la defensa del correcto uso de la artillería, ingenieros militares como Pedro Lucuce insistieron en la necesidad de adaptar los modelos de cañones al uso de las fortificaciones que ocupasen (De Lucuce, 1772: 205-217).

Sobre esta idea insistió Tomás de Morla en su tratado, pues a pesar de reconocer el debate entre fortificación y artillería, reafirmó la necesaria conexión y dependencia existente entre ambas ciencias, ya que «los progresos o atrasos de la una deprime o exalta a la otra». Incluso, Morla afirmó que el diseño de fortificaciones había variado a medida que se perfeccionaban las máquinas para batirlas, por lo que los más imponentes baluartes podían convertirse en ruinas si 
no se defendían con la artillería adecuada (De Morla, 1784: 3-4. Un interesante estudio acerca de los avances científicos obtenidos por Morla es el realizado por De la Gándara Porras, 1999). Ejemplo de ello es la utilización de cañones de a 24 en las baterías de Bocachica, pues al ser la única entrada a la bahía de Cartagena de Indias requería de armas rápidas en el disparo y fáciles de cargar, ajustándose a la función del edificio y al terreno a defender (Fig. 6).

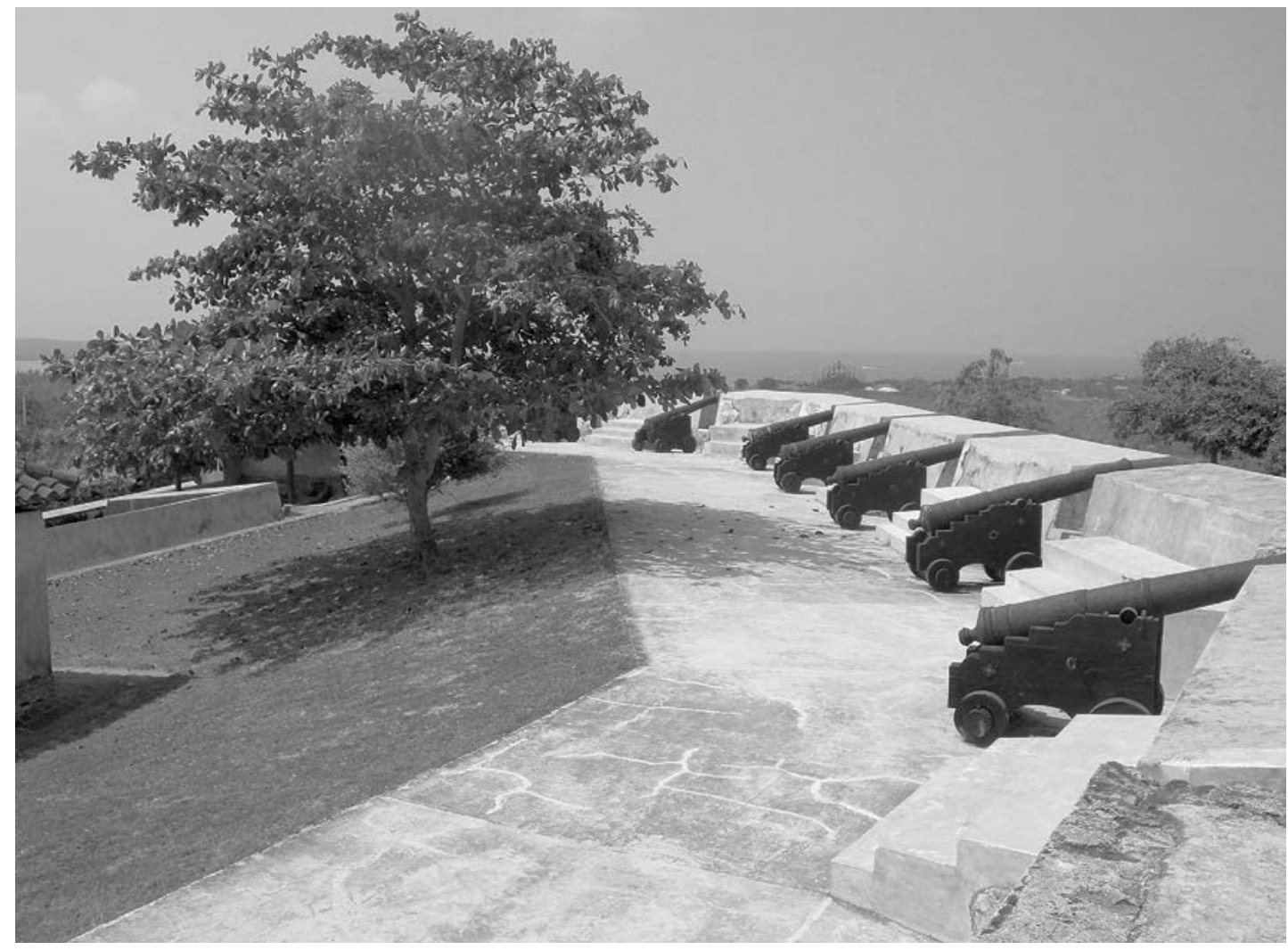

Figura 6. Cañones de la batería del Ángel San Rafael. Tierra Bomba, Cartagena de Indias.

Fotografía del autor.

Otra de las cuestiones que condicionaba el uso eficaz de las armas es el material con el que se fabricaban. Más allá de las diferencias de peso, pues los realizados en bronce eran ligeros y fáciles de transportar, estaba la posibilidad de que los fabricados en hierro explotasen tras varios disparos, amenazando la integridad de los militares y la conservación de la fortificación (Cipolla, 1967: 66). Además, era reconocido por la mayor parte de los artilleros el desarrollo logrado en la fabricación de cañones de bronce en las fábricas peninsulares. Entre estos adelantos, el uso del horno de copela facilitaba la circulación del aire durante el proceso de fusión del cobre y el estaño, lo que aumentaba el grado de oxidación y la pureza del bronce. Mediante este procedimiento se realizaron algunos de los cañones llegados a Cartagena, ciudad únicamente superada por La Habana en el número de dotaciones enviadas desde la Real Fundición de Bronces de Sevilla durante toda la centuria. Al respecto, se contabilizaron en la plaza neogranadina a fines del reinado de Carlos III alrededor de 400 cañones, de los cuales únicamente un 12,5\% eran de bronce (Aguilar Escobar, 2010: 46-47. Igualmente, consúltese De Ocerín, 1972 y De la Vega, 2000). 
El resto del armamento estaba fabricado en hierro y procedía en su mayor parte de la Real Fábrica de Artillería de La Cavada. Fundada en 1622 cerca de Santander, esta factoría se había especializado en la elaboración de cañones férreos sometidos a una serie de nuevas técnicas de fundición (Véase Alcalá-Zamora y Queipo de Llano, 1974). Estos métodos novedosos permitieron la utilización del hierro fundido, esto es, una aleación de distintos metales, entre los que se encontraban el carbono o el silicio, que incrementaba la dureza del cañón y, por tanto, su resistencia final. Así, alcanzado tal grado de perfección técnica y material, los cañones ya no reventaban aunque se sometiesen a continuos disparos, suponiendo un avance en la estrategia defensiva de la Corona. A diferencia de los fabricados en bronce, los cañones

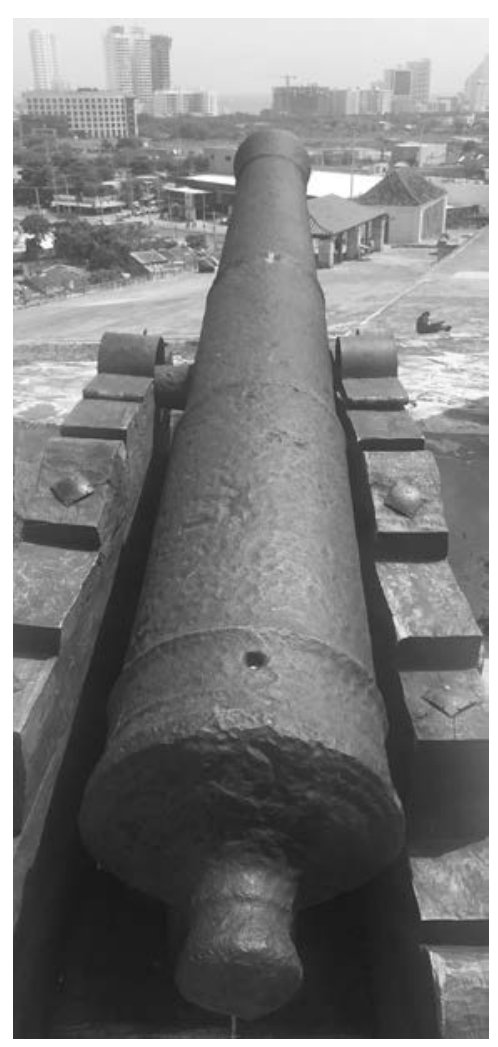

Figura 7. Cañón de hierro fundido en la Real Fábrica de Artillería de La Cavada. de hierro presentaban una estructura externa lisa, pues no fueron profusamente grabados como se muestra en la imagen adjunta (Fig. 7).

En el caso de Cartagena de Indias, la menor utilización de cañones de bronce obedecía a la falta de importación de nuevas piezas desde fines del siglo XVII, utilizándose hasta la segunda mitad del Setecientos los mismos que defendieron la plaza contra el ataque de Pointis. Esta falta de actualización armamentística contrasta con lo experimentado a nivel edilicio, pues durante el siglo XVIII se sucedieron importantes proyectos de fortificación destinados a la protección de la plaza y de la bahía. De este modo, da la impresión de no existir una concordancia entre los distintos Cuerpos e instituciones dedicados al control del territorio, recordándose que ninguna fortificación sería eficaz si adolecía de una artillería adecuada para su defensa. Sin embargo, parece que no influyó en la renovación del armamento la ya aludida fragilidad de aquéllos fabricados en hierro frente al salitre que se acumulaba en la humedad de la bahía de Cartagena de Indias, lo que incentivó las continuas peticiones de cañones de bronce por los castellanos. Denegadas de forma continua tales propuestas, fue obligado el acopio de cañones férreos procedentes de ciudades cercanas e incluso procedentes de barcos, hasta superarse las 400 unidades durante la década de 1760 (Marchena Fernández, 1982: 384-397). Esta obligatoriedad exigía la búsqueda de medidas alternativas que mejorasen la conservación del hierro, ejecutándose al respecto y como ya se ha comentado distintos experimentos por parte de los militares cartageneros para alcanzar tal fin.

Por último, en cuanto al calibre de los cañones empleados, a lo largo del siglo XVIII disminuyó la utilización de los de a 30 y 14 hasta no encontrarse ningún ejemplo de esta tipología a fines de la centuria. El cañón más utilizado en las fortificaciones de Cartagena de Indias fue el de a 24 , caracterizado por una elevada perfección en el disparo, considerándose como el arma de mayor precisión de cuantas se importaron. Con éste se equiparon los distintos baluartes de la muralla del Norte y los fuertes de Bocachica, puntos estratégicos en la conquista de la plaza que debían ser defendidos con la artillería más eficaz en el tiro a larga distancia. Distinto fue el caso del castillo de San Felipe de Barajas, pues se consideró que el calibre de a 16 era el más útil para defender la distancia existente entre el cerro de San Lázaro y la propia plaza. Complementarios a éstos se colocaron otros de menor potencia y peso, como eran los de a 


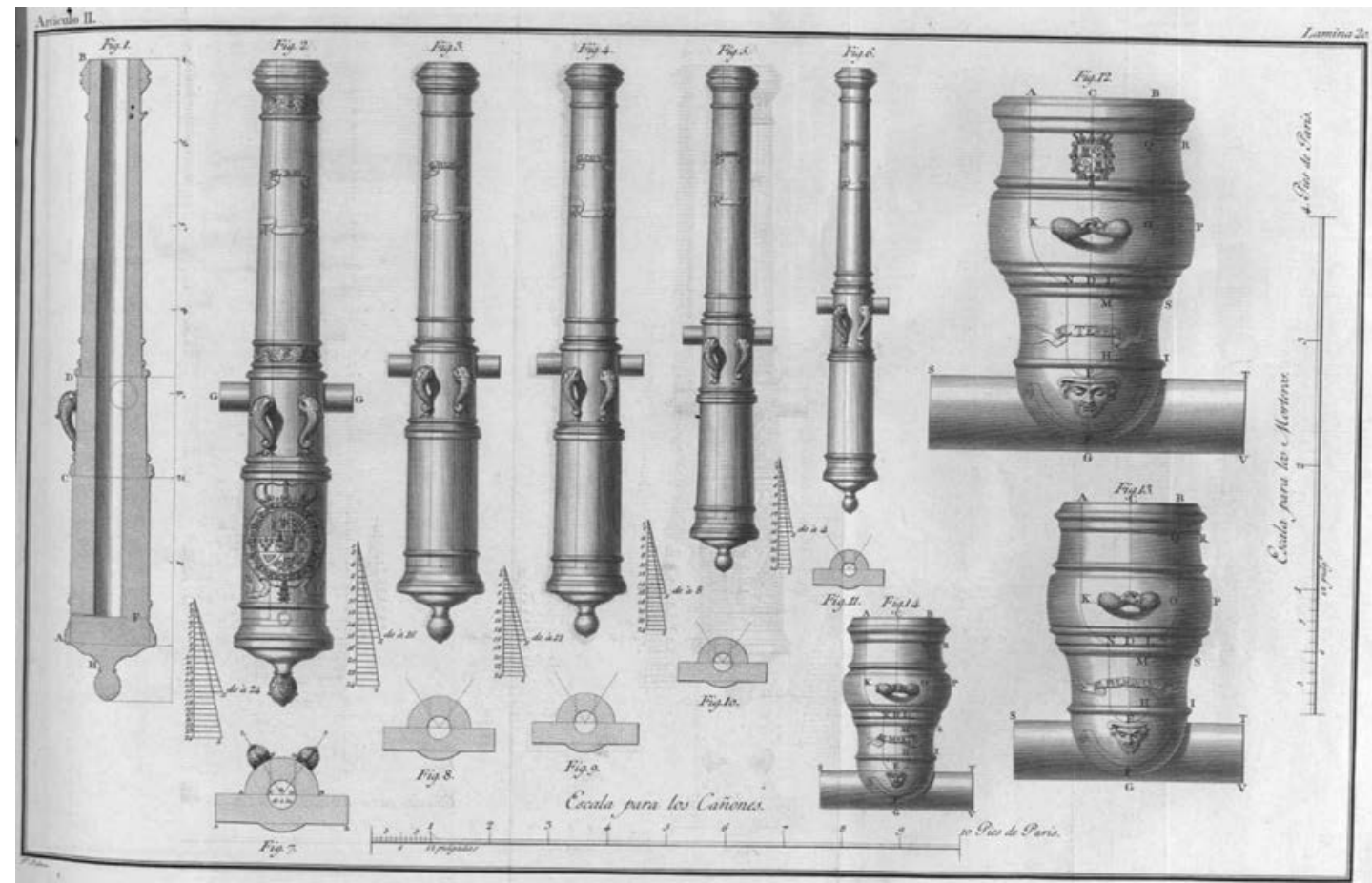

Figura 8. Modelos de cañones. Tomás de Morla (1816). Tratado de Artillería para el uso de la Academia de Caballeros Cadetes del Real Cuerpo de Artillería. Segovia, Imprenta de José Espinosa: vol. IV, lám. 20.

10 ó a 6, ideales para ser trasladados entre las distintas baterías del mencionado castillo o las cortinas de las propias murallas, incrementando la certeza en puntos más alejados y aparentemente vulnerables (Marchena Fernández, 1982: 387). Los distintos modelos utilizados en las fortificaciones de Cartagena de Indias fueron los que de forma convencional se emplearon en otras plazas españolas, recogidos por Tomás de Morla en su tratado como demuestra la lámina que acompaña a estas líneas (Fig. 8).

Según lo comentado, la artillería de Cartagena de Indias necesitaba de una alteración sustancial no solo del número de piezas dispuestas, sino también de la calidad material con las que éstas eran fabricadas. El equipamiento de las nuevas fortificaciones proyectadas durante el reinado de Carlos III contó con armas no siempre eficaces, existiendo una extensa relación epistolar de militares españoles quejándose del deplorable estado del armamento y de la carencia de munición en los almacenes locales (Kuethe, 2005). Igualmente, nunca existió un plan general que legislase la aplicación de medidas preventivas para la conservación de los cañones, siendo consecuencia de esta desidia el desgaste que presentaban muchas piezas desde principios del siglo XVIII. Las principales causas de este deterioro consistían por un lado en la exposición a un clima hostil que dificultaba la preservación del hierro, pues la intensa humedad registrada en la bahía favorecía la aparición de daños y fisuras. Ciertamente, según los datos consultados, la humedad de la costa de Cartagena de Indias supera el $88 \%$ de media anual, dato que refleja un condicionante muy particular del ambiente caribeño (Fuente: Instituto de Hidrología, Meteorología y Estudios Ambientales de Colombia). Por otro lado, hay que tener en cuenta el alto grado de salitre que alberga el ambiente en la bahía de Cartagena de Indias, lo que generaba que dicha sustancia se incrustase en los metales, provocando la sequedad del hierro y la apertura de grietas u oquedades que debilitaban la estructura de las armas. 


\section{BARNIZ DE ÓLEO. LA APLICACIÓN DE UN PRINCIPIO CIENTÍFICO EN LA ARTI- LLERÍA DE CARTAGENA DE INDIAS.}

Para superar la falta de conservación de la artillería en Cartagena de Indias, la Corona envió desde las fábricas peninsulares diversos modelos de cañones fabricados con nuevas técnicas, intentando paliar los efectos de la humedad y del salitre. Así, desde 1765 se mandaron una serie de piezas fabricadas en La Cavada con el ya mencionado hierro fundido para comprobar si resistía al salitre del Caribe. En idéntica fecha, aunque desde Barcelona, llegaron otros cañones de bronce lisos y carentes de decoración, suponiéndose que de esa forma se evitaría la apertura de grietas. Instalados en las fortificaciones de Cartagena de Indias en 1773, el virrey Manuel Guirior le encargó a Domingo Esquiaqui, coronel de artillería, dirigir las comprobaciones mediante varios disparos (El documento en el que el virrey ordenó dicha práctica se conserva en el Archivo General de la Nación de Colombia (en adelante AGN). Sección Colonia. Milicias y Marina. Signatura SC. 37. 67. 135. «Al comitente de Artillería para que la reconozca y pruebe la que haya venido desde el año 1765 en adelante, por sospechar de su mala calidad». Cartagena de Indias. 13 de Febrero de 1773). El interés por parte de las autoridades en demostrar el correcto funcionamiento de los cañones estaba justificado, pues del alcance de éstos dependía la efectividad de parte del sistema defensivo de la ciudad.

No obstante, de entre todos los tratamientos con los que se trató a la artillería de Cartagena de Indias, destacó el experimento practicado en mayo de 1798 y también dirigido por Esquiaqui. Éste, como coronel del Real Cuerpo de Artillería y comandante del departamento, recibió una carta firmada por el virrey José de Espeleta con fecha de febrero de 1796, en la que le instaba a sustituir el antiguo tratamiento de barnizado del cañón con alquitrán por otro que mejorase su conservación, permitiéndole experimentar con seis cañones e igual número de cureñas. Para ello, Esquiaqui reunió en junta de guerra a ilustres militares cartageneros con el fin de discutir las comprobaciones que debían realizar. Pertenecientes al mencionado Cuerpo, los integrantes de la comisión fueron los tenientes coroneles Rafael de Arce, José de Salcedo e Ignacio Yus y los tenientes José Antonio Esquiaqui, José Llach, Juan Rodríguez y Francisco Reina. Como especialistas en artillería, los allí reunidos concluyeron que los desperfectos surgidos en los cañones de hierro eran producto del secado de la capa de alquitrán con la que bañaban las piezas al final del antiguo proceso de fabricación (AGN. Sección Colonia. Milicias y Marina. Signatura SC. 37. 21. 18. «Experimento practicado en la pintura al óleo de seis cañones con sus correspondientes cureñas». Cartagena de Indias. 30 de julio de 1798).

En concreto, el alquitrán se obtenía de la destilación del carbón de piedra mediante la aplicación de un fuego moderado, proceso que generaba un líquido negro pegajoso, maloliente y viscoso que se utilizaba como barniz protector. Con dicho producto se pintaban los cañones de hierro, la munición y todos los herrajes derivados de la artillería. Para ello, el alquitrán resultante se calentaba a altas temperaturas, se dejaba enfriar y posteriormente se aplicaba al cañón. Se pensaba así que esta capa precavería la oxidación del hierro, superando otros procesos de mayor simplicidad en los que se protegía el cañón con varias capas de aceite (Detallada y precisa es la descripción que sobre este proceso recogió el comandante Ramón de Salas en su prontuario sobre artillería, incidiendo en los buenos resultados que el alquitrán había tenido para la protección de los cañones de hierro en Madrid o Sevilla, casos muy distintos a los ocurridos en las ciudades americanas. De Salas, 1833: 350-351).

El buen resultado obtenido tras la aplicación de barniz en los cañones de hierro hallados en las plazas peninsulares fue muy distinto a lo ocurrido en la realidad indiana, donde pasado un tiempo desaparecían las partes grasas de la resina, surgiendo unas costras y pérdidas del revestimiento en el tubo del arma que reducían su potencia y su distancia de tiro. Además, tras varios disparos se recalentaban en exceso, obligando a los soldados a refrescarlos con agua. En 
última instancia el cañón férreo se picaba, saltando incluso pequeñas lascas de forma violenta que destruían otras partes hasta dejarlo inservible, como ocurrió en algunas armas situadas en las fortificaciones de Cartagena de Indias.

Para remediar la falta de adaptación del cañón de hierro al medio caribeño, los comisionados por Esquiaqui buscaron distintas soluciones para vencer tan perjudicial inconveniente, aplicando la solución más eficaz a los seis cañones con sus cureñas permitidos por el virrey. En primer lugar procedieron a limpiar la superficie de dichas armas hasta eliminar las costras y las capas de alquitrán y, posteriormente, aplicaron un compuesto caliente formado por un tercio de sebo, dos de resina y otro de humo de pez (AGN. Sección Colonia. Milicias y Marina. Signatura SC. 37. 21. 18. «Experimento practicado en la pintura al óleo de seis cañones con sus correspondientes cureñas». Cartagena de Indias. 30 de julio de 1798). Este último componente, también llamado negro de humo, era un pigmento formado a partir de la combustión de distintos aceites, resinas y grasas, resultando un barniz enormemente resistente al sol. No fue invención de los mencionados militares la mezcla de dichos productos, pues distintos tratados publicados durante el siglo XVIII recomendaban su utilización. En concreto, el tratadista limeño Pedro Antonio Bracho Bustamante propuso en su escrito publicado en 1764 el uso de una pasta formada por pez, cera y sebo para reparar las oquedades producidas en los cañones por efecto de la humedad y del salitre. Es más, Bracho ya apuntó que la eficacia de tal compuesto era proporcional al grado de salitre que presentase el ambiente, justificando su aplicación en la artillería de Cartagena de Indias (Bracho Bustamante, 1764: 40-42). Incluso, a través del escrito de Bracho se conoce el proceso de aplicación del nuevo óleo. Así, el cañón se colocaba sobre dos piedras de moderada altura y cubierta de leña para quemarla. Cuando el hierro alcanzaba una temperatura elevada se alzaba la boca y se tapaba el fogón de la recámara, procediendo a cubrir el cañón con el compuesto formado por pez, cera y sebo. Tras este proceso se procedía a limpiar el ánima, a rascar la costra resultante en el interior del cañón y a pasar por dentro una lanada mojada en sebo derretido. Finalizada la aplicación del novedoso barnizado, se podía pasar a la prueba de fuego, recomendándose que la pólvora empleada al efecto fuese encartuchada en pergaminos, pues la grasa podía reducir la fuerza del disparo.

Los principios descritos y recogidos por Bracho fueron los utilizados por los militares de Cartagena de Indias para enmendar los problemas de conservación de su artillería. De este modo, tras aplicar el novedoso sistema de barnizado, expusieron los cañones a la intemperie humedeciéndolos continuamente durante el proceso de secado y disparando en varias ocasiones para reconocer la reacción del hierro ante el nuevo tratamiento. Así, el experimento resultó exitoso, ya que pasados seis meses desde que se aplicó el referido betún a los seis cañones, los militares reconocieron que resistirían hasta tres años sin necesidad de repetir el proceso.

A partir de aquí, el nuevo componente ideado por los artilleros destinados en Cartagena de Indias, denominado en la documentación como pintura al óleo, fue aplicándose en distintos cañones situados en varios puntos de las fortificaciones. De entre toda la artillería, se untó en dos cañones de hierro del calibre de a 24 en la batería baja del fuerte de San José de Bocachica, dos idénticos del castillo de San Felipe de Barajas y otros dos en la cortina de Santa Clara. Con ello se pretendía comprobar la reacción del óleo en diferentes puntos de la bahía, advirtiendo del desigual uso de los cañones en función de su localización. Asimismo, se tenía en cuenta que las atmósferas de las distintas fortificaciones variaban, siendo el entorno de San Felipe menos salitroso que el situado en Bocachica, al hallarse a mayor altura sobre el cerro de San Lázaro (Fig. 9). De hecho, se aplicó ese compuesto pensando en la dificultad que presentaba para la conservación de los cañones de hierro el ambiente de la bahía de Cartagena de Indias, pues era bien conocido por los militares que la unión de sebo, pez y cera favorecía la prevención de grietas y oquedades en aquellas armas expuestas a una mayor humedad. Éste era el 
caso de las fortificaciones construidas en el canal de Bocachica, como la batería de San José o del fuerte de San Fernando, cuyos cañones sufrían importantes alteraciones climáticas que repercutían en la acumulación de desperfectos estructurales. Fue precisamente la corrección de estos problemas lo que determinaría si el nuevo barniz podía ser aplicado en el conjunto de la artillería de Cartagena de Indias, lo que remediaría un problema de conservación que afectaba a sus armas desde los primeros años de la conquista.

Pasados siete meses, en febrero de 1799, la comisión pasó a revisar los cañones tratados con el nuevo óleo y situados en las citadas fortificaciones. El resultado fue exitoso, pues el hierro se encontraba en perfecto estado de conservación, no presentando ningún tipo de costra, ni grieta. Si bien, se acordó que en lugar de una mano, se aplicase una segunda para asegurar el resultado final. Con ello, había finalizado un proceso experimental en la conservación de los cañones, dando por acabado el principal problema que afectaba a la conservación de las armas de Cartagena de Indias y al que se enfrentaron los castellanos de sus fortificaciones.

\section{CONCLUSIONES}

La experimentación realizada por los militares españoles en el proceso de barnizado de varios cañones se entiende dentro de un contexto repleto de distintos avances científicos, algunos apuntados en las líneas anteriores, resultados de las nuevas ideas ilustradas llegadas desde distintas zonas de Europa. La publicación de varios tratados capitales sobre el arte artillero durante las primeras décadas del siglo XVIII supuso un estímulo para alcanzar la perfección técnica ansiada en las fábricas de artillería españolas. En este sentido, fueron varios los métodos propuestos para la fundición y fabricación de nuevas armas, incentivando a los militares en la obtención de remedios para los desperfectos existentes en el armamento hispano. Entre

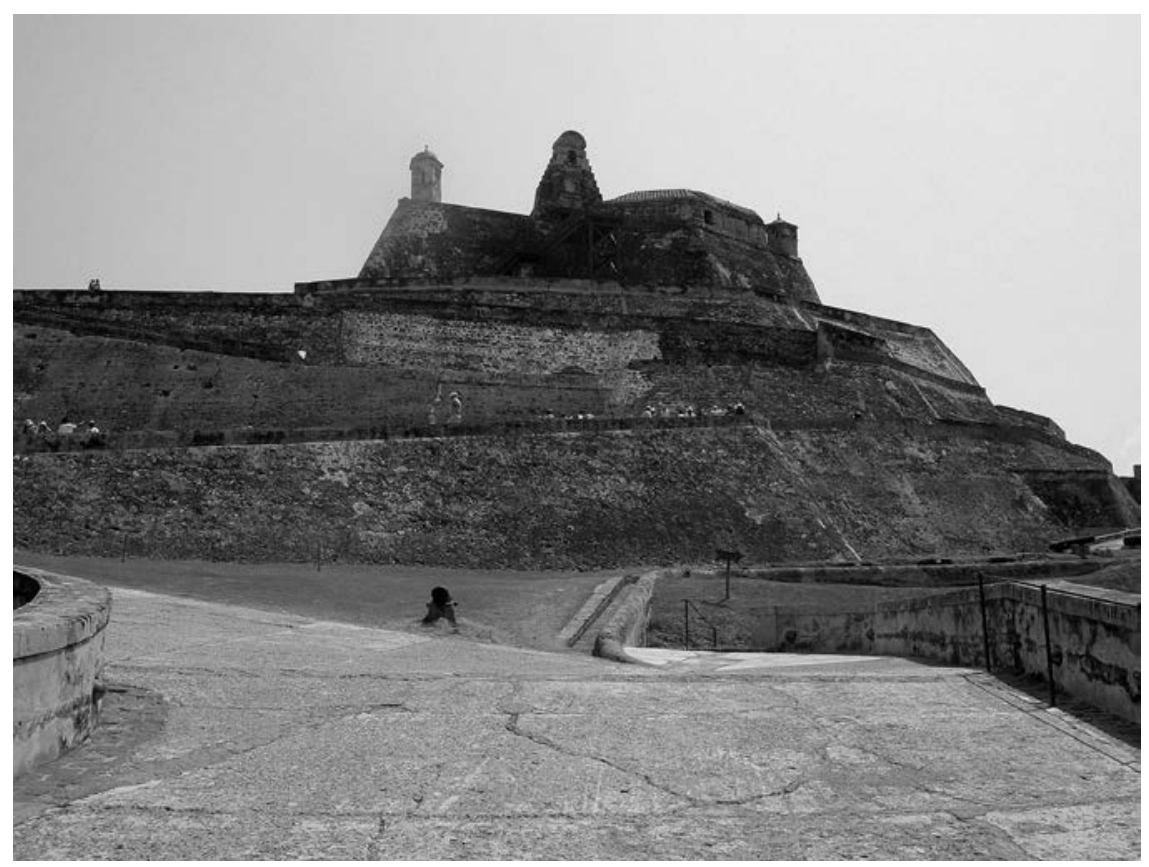

Figura 9. Castillo de San Felipe de Barajas. Cerro de San Lázaro, Cartagena de Indias. Fotografía del autor. 
éstos, la sustitución del viejo alquitranado por una nueva mezcla de aceites y resinas al finalizar el proceso de fundición de los cañones de hierro denota una actualización de las técnicas de fabricación armamentística.

Gracias a estos cambios se solventaron numerosos problemas defensivos que repercutieron en la recuperación de la crisis bélica sufrida durante las décadas centrales del Setecientos. Asimismo, el efecto positivo de tales experiencias trascendía al gasto destinado para la compra de munición y armas, pues con la práctica de estas medidas de conservación de los pertrechos de guerra se descartaba la adquisición de nuevos cañones, suponiendo un beneficio para las arcas estatales. En definitiva, se afrontó un problema común en todas las plazas españolas del Caribe, donde la presencia inglesa suponía una continua amenaza para la que se debían preparar las fortificaciones y el armamento. No obstante, no fue hasta la implantación en los talleres españoles de los nuevos avances tecnológicos cuando se realizaron distintos experimentos para solucionar los problemas expuestos. Tales progresos fueron propios de una novedosa cultura artillera introducida en España por los Borbones tras la firma de los Pactos de Familia, generando una transmisión de las exitosas teorías que sobre defensa publicaron los citados La Vallìere y Gribeauval. Todo ello incrementó el deseo de las autoridades españolas por alcanzar la perfección en el diseño y la fundición de nuevas piezas de artillería, no siendo hasta el reinado de Carlos III cuando se abogó por cambiar los modelos de fabricación artillero intactos desde el siglo XVI, aportándose en este texto un ejemplo de adaptación por parte del ejército a las dificultades que presentaba un mar tan codiciado por las potencias europeas presentes en las Indias.

\section{BIBLIOGRAFÍA}

Aguilar Escobar, A. (2010): Cañones de bronce para el ejército. Historia de la Real Fundición de Sevilla en el siglo XVIII. Madrid, Ministerio de Defensa.

Alcalá- Zamora y Queipo de Llano, J. (1974): Historia de una empresa siderúrgica española: los altos hornos de Liérganes y La Cavada, 1622-1834. Santander, Diputación Provincial.

Alder, K. (1997): Engineering the revolution: arms and enlightenment in France, 1763-1815. Chicago, University Press.

Andújar Castillo, F. (2004): El sonido del dinero. Monarquía, ejército y venalidad en la España del siglo XVIII. Madrid, Marcial Pons Ed.

Azpiroz y Arizcun, M. (1875): Fabricación de las piezas de artillería y proyectiles de hierro colado. Segovia, Imprenta Luis Jiménez.

Baeza Martín, A. (2005) «Fundición de Artillería en Nueva España: proyectos fallidos, la alternativa a Sevilla (1722-1794)», A. Gutiérrez Escudero y M. L. Laviana Cuetos (coords.), Estudios sobre América. Siglos XVI-XX. Sevilla, Asociación Española de Americanistas: 879-904.

Barba, Á. (1640): Arte de los metales: en que se enseña el verdadero beneficio del oro y la plata por azogue, el modo de fundirlos todos y como se han de refinar y apartar unos de otros. Madrid, Imprenta del Reino.

Bigot, S. F. (1737): Essay de l'application des forces centrales aux effets de la poudre à canon, d'où l'on déduira une théorie propre à perfectionner les différentes bouches à feu. París, Libraire du Roy.

Bracho Bustamante, P. A. (1764): Tratado de artillería y bombardería para instrucción de los artilleros. Lima, Imprenta Real.

Calderón Quijano, J. A. (1942): «¿Pensó Vernon utilizar las cortinas de humo en su ataque de Cartagena en 1741?». Revista General de Marina, CXXII: 651-655.

Cipolla, C. (1967): Cañones y velas. Barcelona, Ariel.

Cisneros Guerrero, G. (2003): «Proyecto de los ingenieros Pedro Ponce y Diego Panes para establecer una fundición de artillería en la Nueva España, siglo XVIII». Revista Bibliográfica de Geografía y Ciencias Sociales, 447: s/n. 
Claro Delgado, M. (1997): «La artillería en la defensa de Centroamérica en el siglo XVIII». Militaria. Revista de Cultura Militar, 10: 125-138.

Collado, L. (1592): Plática manual de artillería en la cual se trata de la excelencia del arte militar. Milán, Librería Paolo Gotardo Stampador de la Real Cámara.

De la Gándara Porras, M. Del P. (1999): «Tomás Bruno de Morla y Pacheco: militar de artillería, científico, docente y político», AA.VV, Milicia y sociedad en la baja Andalucía (siglos XVIII y XIX). Sevilla, Deimos: 261-272.

De la Vega Viguera, E. (2000): Sevilla y la Real Fundición de cañones. Sevilla, Ediciones Guadalquivir.

De Lucuce, P. (1772): Principios de fortificación. Barcelona, Impresor real Thomas Piferrer.

De Morla, T. (1784): Tratado de Artillería para el uso de la Academia de Caballeros Cadetes del Real Cuerpo de Artillería. Segovia, Imprenta Antonio Spinosa.

De Ocerín, E. (1972): Apuntes para la historia de la Fábrica de Artillería de Sevilla. Madrid, Imprenta Real Fábrica de Artillería.

De Salas, R. (1833): Prontuario de Artillería para el servicio de campaña. Madrid, Impresor de Cámara de S.M.

Díaz Infante, J. (1740): Pirometalia absoluta o arte de fundidores. Palma, Imprenta de Miguel Cerdá.

Flores Morón, B. L. (1997): «Hacia una evolución de los costos de la Artillería americana en el siglo XVIII». Militaria. Revista de Cultura Militar, 10: 95-104.

Gámez Casado, M. (2017a): «La invasión de las arenas. Proyectos para la limpieza del foso del fuerte de San Fernando en Cartagena de Indias». Temas Americanistas, 39: 67-86.

Gámez Casado, M. (2017b): «Ingenieros militares y arquitectura defensiva en Cartagena de Indias tras el ataque del barón de Pointis». AA.VV, De Sur a Sur. Intercambios artísticos y relaciones culturales. Granada, Editorial Universidad: 179-183.

Gámez Casado, M. (2018): «Buscando al enemigo inglés. Expediciones de guardacostas españoles al golfo del Darién, 1767-1768». Anuario de Estudios Americanos, 75 (1): 211-236.

Gómez Pérez, C. (1985): «El Consulado de Sevilla y la formación de las oligarquías en Cartagena de Indias a principios del siglo XVIII». B. Torres Ramírez y J. Hernández Palomo (coords.), Andalucía y América en el siglo XVIII. IV Jornadas de Andalucía y América. La Rábida, Editorial Universidad: 329-348.

Gómez Pérez, C. (1997): «El problema logístico y la operatividad de la Artillería en América». Militaria, Revista de Cultura Militar, 10: 43-56

Helguera Quijada, J. (1983): «Primeros intentos de renovación tecnológica en la Fundición de Artillería a mediados del siglo XVIII. 1757-1765». AA.VV, Actas II Coloquio Historia de Andalucía. Córdoba, Editorial Universidad: 467-479.

Kuethe, A. (1974): «La batalla de Cartagena en 1741». Historiografía y bibliografia americanista, XVIII: $18-38$.

Kuethe, A. (2005): «Carlos III, absolutismo ilustrado e imperio americano». A. Kuethe y J. Marchena (eds.), Soldados del Rey. El ejército borbónico en América colonial en vísperas de la Independencia. Castellón, Publicaciones Universitat Jaume I: 17-30.

Kuethe, A. y Kennet, A. (2014): The spanish Atlantic World in the Eighteenth Century. War and the Bourbon Reforms, 1713- 1796. Nueva York, Cambridge University Press.

López Guzmán, R. y Cabrera Cruz, A. R. (2017): «La visión del virrey Sebastián de Eslava del asedio de Cartagena de Indias en 1741. El funcionamiento de las fortificaciones». P. Cruz Freire y I. J. López Hernández (coords.), Ingeniería e ingenieros en la América Hispana. Siglos XVIII y XIX. Sevilla, Editorial Universidad: 49-75.

López Piñero, J. M. (1988): «Impulso y desarrollo de la actividad científica». AA.VV., Carlos III y la Ilustración. 1988, Comisión Bicentenario: 265-278.

Lucena Salmoral, M. (1973): «Los diarios anónimos sobre el ataque de Vernon a Cartagena existentes en Colombia: su correlación y posibles autores». Anuario de Estudios Americanos, XXX: 337-469.

Marchena Fernández, J. (1982): La institución militar en Cartagena de Indias en el siglo XVIII. Sevilla, CSIC.

Mora Piris, P. (1997): «Revalorización científica de la industria metalúrgica de Artillería en el siglo XVIII». Militaria. Revista de Cultura Militar, 10: 325-348.

Mora Piris, P. (1993): La Real Fundición de Bronces de Sevilla. Sevilla, Escuela Superior de Ingenieros. 
Morales, A. J. (2016): «América y los ingenieros de Carlos III». E. Almarcha Núñez- Herrador, E. Martínez Burgos y E. Sainz Magañan (eds.), El Greco en su IV Centenario: Patrimonio Hispánico y diálogo cultural. Toledo, Editorial Universidad Castilla La-Macha: 67-78.

Rabanal Yus, A. (1990): Las reales fundiciones españolas del siglo XVIII. Madrid, Servicio de Publicaciones del EME.

Restrepo Canal, C. (1941): «El sitio de Cartagena por el almirante Vernon». Boletín de Historia y Antigüedades, XXVIII: 447-467.

Rodríguez Casado, V. (1956): «El ejército y la marina en el reinado de Carlos III». Boletín del Instituto de Riva Agüero, 12: 129-156.

Serrano Álvarez, J. M. (2016): «El éxito de la escasez. La defensa de Cartagena de Indias en 1741». Vegueta, 16: 359-383.

Velásquez Arango, J. J. (2015): «La empresa y estanco de pólvora en el virreinato del Nuevo Reino de Granada, 1772-1810». Quirón, 2: 35-44.

Vernon, E. (1744): Authentic papers relating to the expedition against Carthagena. Londres, Printed L. Raymond.

Vigón, J. (1947): Historia de la artillería española. Madrid, CSIC.

Zapatero, J. M. (1957): «La heroica defensa de Cartagena ante el almirante inglés Vernon». Revista de Historia Militar, 1: 115-152.

Zapatero, J. M. (1979): Historia de las fortificaciones de Cartagena de Indias. Madrid, CEHOPU.

Recibido: 09-10-2017

Aceptado: 26-03-2018 